\title{
PENGENDALIAN KUALITAS STATISTIK TOTAL SUSPENDED SOLID PADA STOCK PREPARATION 1 DI PT X (INDUSTRI KERTAS)
}

\author{
Rini Anggraini ${ }^{1)}$, Bagas Atma $\mathbf{P}^{2}$ ), Popy Yuliarty $^{3)}$ \\ 1) Prodi Teknik Mesin, Universitas Mercu Buana \\ 2,3) Prodi Teknik Industri, Universitas Mercu Buana \\ rini_anggraini@mercubuana.ac.id
}

\begin{abstract}
Abstrak. PT. X merupakan sebuah perusahaan yang bergerak dalam bidang produksi kertas. Salah satu seksi induk $\mathrm{X}$ adalah bagian Stock Preparation. Stock Preparation mempunyai tugas fundamental, yaitu mengubah waste paper menjadi pulp atau bubur kertas sebelum menjadi produk jadi yaitu kertas. Kualitas air merupakan salah satu hal terpenting dalam Stock Preparation 1, baik itu berupa air proses maupun air limbah. Di Stock Preparation, parameter penilaian kualitas air limbah dapat dilihat dari jumlah Total Suspended Solid (TSS) yang terkandung di dalam sewer. Data yang digunakan untuk kualitas air pada Total Suspended Solid di Stock Preparation 1 dengan menggunakan metode Control Chart yaitu merupakan salah satu dari alat QC 7 tools (7 alat pengendalian kualitas) yang berbentuk grafik dan dipergunakan untuk memonitor atau memantau stabilitas dari suatu proses serta mempelajari perubahan proses dari waktu ke waktu. Tujuannya agar air yang dibuang ke lingkungan tidak mencemari lingkungan sekitar. Hasil yang di peroleh menggunakan metode ini, sebesar $1606 \mathrm{mg} / \mathrm{L}$ dan tergolong kedalam golongan yang tidak mencemari lingkungan. Hasil penelitian ini adalah data out of control yaitu pada data ke - 8 yang disebabkan karena nilai konsentrasi TSS yang tinggi (melebihi standar yang ditetapkan).Penyebab konsentrasi TSS tinggi adalah pompa ada yang bocor sehingga air masuk ke sewer, Line Production Stop karena tangki penyaringan dikuras, overflow yaitu kelebihan aliran air di dalam tangki sehingga output tidak keluar dan screen (Penyaring) jenis STS mengalami PLUG, dalam kata lain saringan tersumbat.
\end{abstract}

Kata Kunci: Stock Preparation, Total Suspended Solid, Control Chart

\section{PENDAHULUAN}

Perkembangan industri di Indonesia yang semakin maju secara tidak langsung memacu para pemilik perusahaan untuk terus berkembang. Setiap perusahaan berusaha untuk memenuhi permintaan konsumen agar tidak kehilangan konsumen utama. Proses produksi yang efektif dan efisien adalah sesuatu yang ingin dicapai setiap perusahaan manufaktur saat ini. $\mathrm{X}$ tampil sebagai produk dari suatu pengaruh yang besar sebagai akibat dari perkembangan bisnis Indonesia pada tingkat pasar domestik dan Internasional. $\mathrm{X}$ adalah anak perusahaan yang tak langsung dari Asia Pulp \& Paper Co.Ltd, perusahaan dari Singapura yang merupakan perusahaan pulp \& paper terbesar dan terintegrasi di Asia.

Suspended Solid merupakan parameter yang penting untuk di analisa sejauh mana padatan tersuspensi pada air sampel. Suspended Solid adalah kandungan partikel-partikel zat padat yang tersuspensi dalam air yang dapat dipisahkan dari penyaringan. Bertujuan untuk mengukur kandungan partikel zat padat yang tidak larut dalam air. Suspended Solid yang melebihi ambang batas akan menyebabkan bercak-bercak pada produk kertas, juga akan berpengaruh pada tingginya penambahan bahan kimia. Parameter Suspended Solid adalah parameter air yang penting untuk menyatakan tingkat pencemaran air dan layak tidaknya air tersebut dapat digunakan.

Pengendalian merupakan suatu proses dalam mengarahkan sekumpulan variabel untuk mencapai tujuan dan sasaran yang telah ditetapkan sebelumnya. Dasar dari semua proses pengendalian adalah pemikiran untuk mengarahkan suatu variabel atau sekumpulan variabel guna mencapai tujuan tertentu. Variabel yang dimaksud berupa manusia, mesin dan organisasi. Pengendalian diperlukan karena 
adanya 2 alasan (Evans dan Lindsay, 2007) yaitu :

1. Pengendalian merupakan dasar bagi manajemen kerja harian yang efektif bagi semua tingkatan organisasi.

2. Perbaikan jangka panjang tidak dapat diterapkan pada suatu proses kecuali jika proses tersebut terkendali dengan baik.

Pengertian pengendalian kualitas menurut Sofyan Assauri (1998) adalah "Pengawasan mutu merupakan usaha untuk mempertahankan mutu/kualitas barang yang dihasilkan, agar sesuai dengan spesifikasi produk yang telah ditetapkan berdasarkan kebijaksanaan pemimpin perusahaan."

Fokus penelitian ini adalah untuk mengetahui berapa jumlah rata - rata Total Suspended Solid pada line Stock Preparation 1 di PT. X dan mengendalikan kualitas air yang dilakukan pada line Stock Preparation 1 menggunakan metode Peta Kendali (Control Chart).

\section{METODE PENELITIAN}

Penelitian ini menggunakan model kuantitatif dan model kualitatif atau dengan kata lain model campuran. Tahapan penelitian dapat dijelaskan sebagai berikut :

1. Survey lapangan untuk mengetahui potensi masalah dari objek penelitian

2. Berdasarkan survey awal, maka peneliti dapat merumuskan masalah dalam penelitian ini yaitu bagaimana mengetahui berapa jumlah rata - rata Total Suspended Solid pada line Stock Preparation 1 di PT. X dan cara untuk mengendalikan kualitas air yang dilakukan pada line Stock Preparation 1 menggunakan metode Peta Kendali (Control Chart).

Peta Kendali $\bar{X}$

$$
\begin{aligned}
& \mathrm{CL}=\bar{X} \\
& \mathrm{UCL}=\bar{X}+\mathrm{A}_{2} \bar{R} \\
& \mathrm{LCL}=\bar{X}-\mathrm{A}_{2} \bar{R} \\
& \quad \text { Peta Kendal } \\
& \mathrm{CL}=\overline{\bar{R}} \\
& \mathrm{UCL}=\mathrm{D}_{4} \cdot \bar{R} \\
& \mathrm{LCL}=\mathrm{D}_{3} \cdot \bar{R}
\end{aligned}
$$$$
\text { Peta Kendali R }
$$

Catatan: Untuk nilai $\mathrm{A}_{2}, \mathrm{D}_{3}$ dan $\mathrm{D}_{4}$

3. Batasan-batasan dalam penelitian ditetapkan agar pembahasannya dapat fokus kepada masalah utama

4. Melakukan pengolahan data dengan menggunakan tools peta kendali $\mathrm{X}$ dan R. Nilai $\bar{X}$ yang merupakan perhitungan rata-rata, didapatkan dengan rumus: $\bar{X}=\frac{\sum \mathrm{X}}{\mathrm{k}}$, Nilai $\bar{R}$ yang merupakan perhitungan rata-rata, didapatkan dengan rumus:

$$
\bar{R}=\frac{\sum \mathrm{R}}{\mathrm{k}}
$$

5. Melakukan analisis terhadap hasil penelitian

6. Penarikan kesimpulan berdasarkan hasil tang didapatkan

\section{HASIL DAN PEMBAHASAN}

Suspended solid adalah salah satu parameter air yang sangat penting untuk menyatakan tingkat pencemaran air dan layak tidaknya air tersebut digunakan. Dalam kata lain. Total Suspended Solid yaitu padatan yang terdapat pada aliran di suatu mesin. Data Total Suspended Solid (TSS) dapat dilihat pada Tabel 1 berikut ini : 
Tabel 1. Data Total Suspended Solid (TSS) di Stock Preparation 1 (Juni 2018)

\begin{tabular}{|c|c|c|c|c|c|}
\hline Date & $\begin{array}{c}\text { Standard } \\
\text { Max. } \\
(\mathbf{m g} / \mathbf{L})\end{array}$ & 08.00 - 12.00 & $16.00-20.00$ & $24.00-04.00$ & Average \\
\hline 1 & \multirow{30}{*}{2.500} & 1,574 & 1,075 & 1,159 & 1.269 \\
\hline 2 & & 0,970 & 1,821 & 1,074 & 1.288 \\
\hline 3 & & 2,256 & 1,196 & 1,499 & 1.650 \\
\hline 4 & & 1,891 & 1,086 & 1,714 & 1.564 \\
\hline 5 & & 1,569 & 2,390 & 2,110 & 2.023 \\
\hline 6 & & 1,350 & 1,677 & 1,557 & 1.528 \\
\hline 7 & & 1,628 & 1,604 & 2,013 & 1.748 \\
\hline 8 & & 2,622 & 1,822 & 1,969 & 2.138 \\
\hline 9 & & 1,427 & 1,290 & 1,841 & 1.519 \\
\hline 10 & & 1,631 & 1,742 & 1,339 & 1.571 \\
\hline 11 & & 1,764 & 1,691 & 1,265 & 1.573 \\
\hline 12 & & 1,707 & 1,383 & 1,880 & 1.657 \\
\hline 13 & & 1,697 & 2,152 & 1,427 & 1.759 \\
\hline 14 & & 2,054 & 1,113 & 1,172 & 1.446 \\
\hline 15 & & 1,170 & 1,393 & 1,713 & 1.425 \\
\hline 16 & & 1,326 & 1,773 & 1,330 & 1.476 \\
\hline 17 & & 1,656 & 1,593 & 1,747 & 1.665 \\
\hline 18 & & 1,583 & 1,080 & 1,370 & 1.344 \\
\hline 19 & & 1,599 & 1,259 & 1,667 & 1.508 \\
\hline 20 & & 1,370 & 1,700 & 1,363 & 1.478 \\
\hline 21 & & 1,252 & 1,792 & 2,012 & 1.685 \\
\hline 22 & & 2,166 & 2,061 & 1,850 & 2.026 \\
\hline \multirow[t]{2}{*}{23} & & 1,289 & 1,560 & 1,445 & 1.431 \\
\hline & & 1,213 & 1,415 & 1,756 & 1.461 \\
\hline 25 & & 1,547 & 1,645 & 1,670 & 1.621 \\
\hline 26 & & 1,776 & 2,127 & 1,812 & 1.905 \\
\hline 27 & & 1,628 & 1,359 & 1,465 & 1.484 \\
\hline 28 & & 1,930 & 1,651 & 1,772 & 1.784 \\
\hline 29 & & 1,781 & 1,310 & 1,589 & 1.560 \\
\hline 30 & & 1,443 & 1,759 & 1,567 & 1.590 \\
\hline
\end{tabular}

Sumber: PT. X

Nilai $\bar{X}$ yang merupakan perhitungan rata-rata, didapatkan dengan rumus:

$\bar{X}=\frac{\sum \mathrm{X}}{\mathrm{k}} \quad \bar{X}=\frac{4 \quad .3}{3}=1.606$

Nilai $\bar{R}$ yang merupakan perhitungan rata-rata, didapatkan dengan rumus:
$\bar{R}=\frac{\sum \mathrm{R}}{\mathrm{k}} \bar{R}=\frac{1}{3}=509$

Perhitungan dari data Total Suspended Solid di Stock Preparation 1 setelah dikalikan 1000 dapat dilihat pada Tabel 2 berikut ini : 
Tabel 2 Perhitungan Total Suspended Solid (TSS) Juni 2018

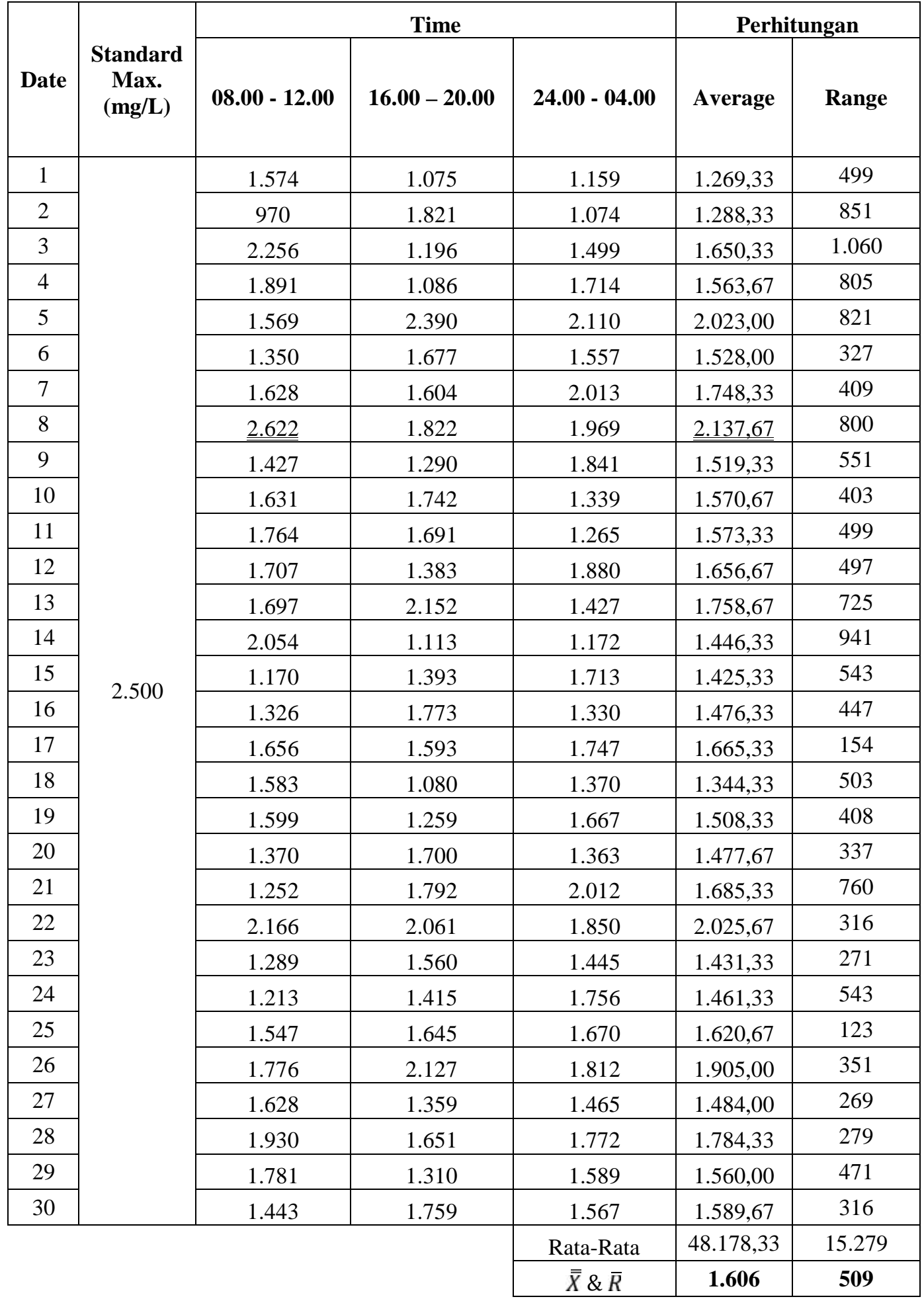

Dari hasil perhitungan di atas dapat digambarkan grafik peta kendali $\bar{X}$ untuk Total Suspended Solid menggunakan software Minitab 17, dapat dilihat pada Gambar 1 berikut ini : 


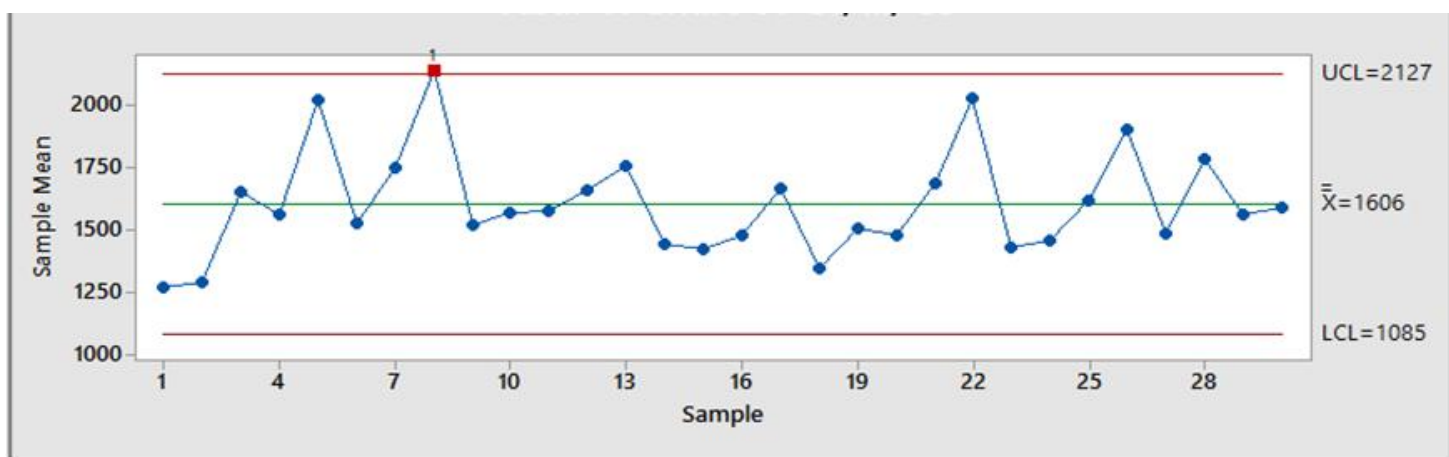

Gambar 1. Grafik peta kendali $\overline{\boldsymbol{X}}$ untuk TSS

Berdasarkan Gambar 1, total Suspended Solid di Stock Preparation 1 pada bulan Juni, terdapat satu data yang out of control yaitu pada data ke - 8. Ini disebabkan karena nilai konsentrasi TSS yang tinggi (melebihi standar yang ditetapkan).Penyebab konsentrasi TSS tinggi:

1. Pompa ada yang bocor sehingga air masuk ke sewer

2. Line Production Stop karena tangki penyaringan dikuras
3. Overflow, yaitu kelebihan aliran air di dalam tangki sehingga output tidak keluar.

4. Screen (Penyaring) jenis STS mengalami PLUG, dalam kata lain saringan tersumbat Dari hasil perhitungan tabel dapat digambarkan grafik peta kendali $\bar{R}$ untuk Total Suspended Solid menggunakan software Minitab 17, dapat dilihat pada gambar 4.2 berikut ini :

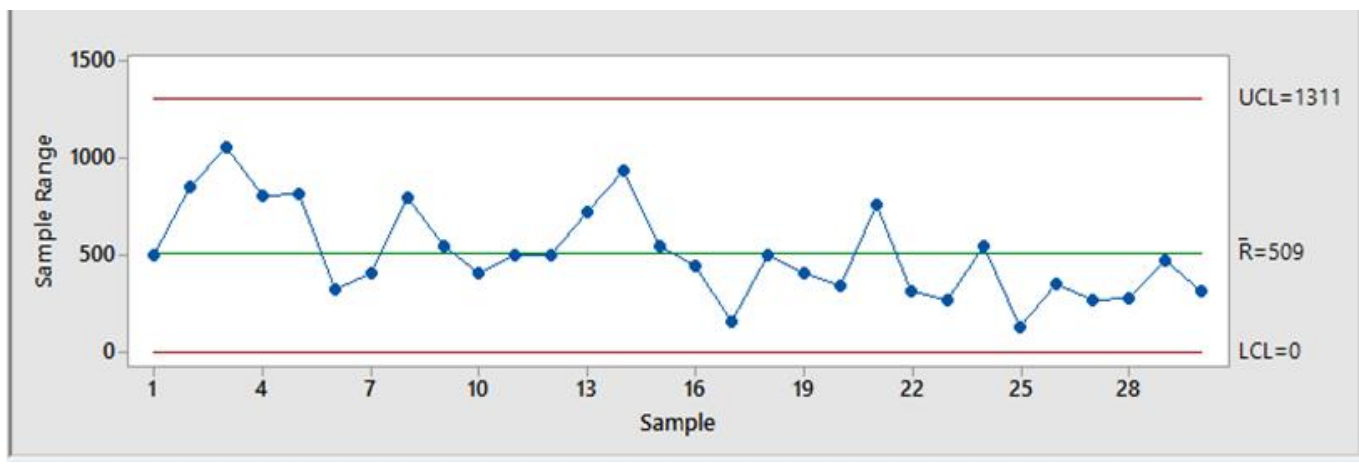

Gambar 2 Grafik peta kendali $\overline{\boldsymbol{R}}$ untuk TSS di Stock Preparation 1

Berdasarkan Gambar 2, Range Total Suspended Solid di Stock Preparation 1 pada bulan Juni, yaitu range sudah dalam batas kendali serta tingkat keakurasian tinggi dan stabil. Hal ini berarti, bahwa para operator bekerja (dalam hal ini melakukan pengamatan) dengan baik di bulan ini, karena tidak ada yang melebihi atau kurang dari batas kendali. Standar kualitas air sudah sesuai dengan yang sudah ditetapkan.

\section{KESIMPULAN}

1. Berdasarkan hasil perhitungan yang dilakukan bahwa pada data Total Suspended Solid memiliki nilai rata-rata yaitu $1606 \mathrm{mg} / \mathrm{L}$ dari standar maksimum yaitu sekitar $2500 \mathrm{mg} / \mathrm{L}$. Masih ada data yang melebihi batas kontrol, itu disebabkan karena nilai konsentrasi Total

Suspended Solid yang tinggi (melebihi standar yang ditetapkan). Sedangkan untuk hasil perhitungan range, data menunjukan bahwa range sudah dalam batas kendali serta tingkat keakurasian tinggi dan stabil. 
2. Dengan menggunakan peta kendali (control chart) untuk menghitung Total Suspended Solid, hal ini menunjukan bahwa pengendalian kualitas air sewer pada line Stock Preparation 1 sudah cukup terkendali, namun perlu dilakukan perbaikan kualitas secara berkelanjutan

\section{DAFTAR PUSTAKA}

[1]. Assauri, S. 1998. Manajemen Produksi dan Operasi. Jakarta: Fakultas Ekonomi Universitas Indonesia.

[2]. Crosby, P. B. 1979. Quality Is Free. New York: McGraw-Hill.

[3]. Deming, W. E. 1982. Out of the Crisis Quality, Productivity and Competitive Position. Cambridge University Press.

[4]. Evans, J. R., dan Lindsay, W. M. 2007. An Introduction to Six Sigma \& Process Improvement (Pengantar Six Sigma). Jakarta: Penerbit Salemba Empat.

[5]. Feigenbaum, A. V. 1986. Total Quality Control. Singapore: Mc Graw Hill Book Co.

[6]. Garvin, D. A. 1988. Managing Quality. New York: The Free Press.

[7]. Gaspersz, V. 1998. Production Planing and Inventory Control. Jakarta: PT. Sun.

[8]. Gaspersz, V. 2001. ISO 9001:2000 and Continual Quality Improvement. Jakarta: PT Gramedia Pustaka Utama. (continues improvement) agar kualitas air yang di buang ke sungai sesuai dengan standar yang sudah ditetapkan dan air limbah yang diolah tersebut telah aman untuk dibuang ke sungai dan tidak merusak lingkungan sekitar.

[9]. Gaspersz, V. 2005. Total Quality Management. Jakarta: PT Gramedia Pustaka Utama.

[10]. Goetsch, D. L., dan Davis, S. B. 2000. The Total Quality Approach to Quality Management: Third Edition. New Jersey: Prentice Hall.

[11]. Heizer, J., dan Render, B. 2005. Operation Management Seventh Edition. New Jersey: Prentice Hall.

[12]. Juran, J. M. 1993. Quality Planning and Analysis: Third Edition. New York: McGraw Hill Book Inc.

[13]. Mullins, J. W., Orville, C. Walker Jr., Larreche J. C., and Boyd H. W. 2005. Marketing Management: A Strategic Decision Making Approach, Fifth Edition. New York: The Mc Graw - Hill companies.

[14]. Smith, G. 2003. Statistical Process Control and Quality Improvement. New Jersey, Prentice Hall. 